\title{
Vanadium(III) binding strengths of small biomolecules*
}

\author{
Péter Buglyół, Eszter Márta Nagy, and Imre Sóvágó \\ University of Debrecen, Department of Inorganic and Analytical Chemistry, \\ P.O. Box 21, H-4010 Debrecen, Hungary
}

\begin{abstract}
The hydrolysis of vanadium(III) and the complex formation reactions between $\mathrm{V}$ (III) and weakly coordinating [glycine (GLY), DL-aspartic acid (ASP), D-penicillamine (PEN), DL-histidine (HIS)] or strongly coordinating [N,O] donor [picolinic (PIC) or 6-methylpicolinic acid (MePIC)] and [O,O] donor [maltol (MALT), 1,2-dimethyl-3-hydroxy4-(1H)-pyridinone (DHP), tiron (TIR)] ligands were studied at $25.0^{\circ} \mathrm{C}$ and an ionic strength of $0.20 \mathrm{M}(\mathrm{KCl})$ in aqueous solution using combined $\mathrm{pH}$-potentiometric and $\mathrm{UV}$-vis spectroscopic techniques. Although some interaction between the amino acids and V(III) was found, we could not obtain reliable models for these systems owing to the intensive hydrolysis of the metal ion and the formation of polynuclear hydroxo complexes. With pyridine carboxylates or $[\mathrm{O}, \mathrm{O}]$ donor ligands 1:1, 1:2 (in the latter case, also 1:3 species) were found to be present as major complexes in solution. The similarities and differences in binding V(III) by these ligands are discussed.
\end{abstract}

Keywords: Vanadium(III); insulin mimetic complex; complex equilibria; picolinate; deferriprone; maltol; speciation.

\section{INTRODUCTION}

Numerous vanadium complexes have already been synthesized, tested in vitro or in vivo and found to have oral insulin mimetic activity [1-5]. However, it was demonstrated only recently that stable, neutral, air-resistant, lipophilic, but water-soluble V(III) complexes with low toxicity may also serve as insulin-enhancing pro-drugs in addition to the more common $\mathrm{VO}(\mathrm{IV})$ or $\mathrm{VO}(\mathrm{V}) / \mathrm{VO}_{2}(\mathrm{~V})$ compounds [6]. Although V(III) complexes are likely to be oxidized rapidly in vivo to $\mathrm{VO}(\mathrm{IV})$ and $\mathrm{V}(\mathrm{V})$ at physiological $\mathrm{pH}$, the difference in coordination chemistry of $\mathrm{V}(\mathrm{III})$ and $\mathrm{VO}(\mathrm{IV})$ or $\mathrm{V}(\mathrm{V})$ may lead to fine-tuning of hydrophilic/lipophilic balance of the potentially active complexes to be taken up in the body. Furthermore, combinations of antioxidants and complexed V(III) are also being tested for antitumor activity [7].

The number of solution equilibrium studies on V(III) systems is very limited in the literature, although solution speciation results may help understand the coordination chemistry of $\mathrm{V}$ (III) and design new ligands. The amount of equilibrium data is limited mainly because of the strong tendency of V(III) to get oxidized under aerobic conditions and its intensive hydrolysis even below $\mathrm{pH}=2$ in aqueous solution. This prompted us first to work out the technical details of the preparation and storage of V(III) stock solutions and then to study the hydrolysis of the metal ion under our experimental conditions.

\footnotetext{
*Paper based on a presentation at the $4^{\text {th }}$ International Symposium on Chemistry and Biological Chemistry of Vanadium, Szeged, Hungary, 3-5 September 2004. Other presentations are published in this issue, pp. 1497-1640.

¥Corresponding author: E-mail: buglyo@delfin.unideb.hu
} 
Now, in the framework of our studies dealing with the solution equilibrium properties of the different oxidation states of vanadium, we wish to present our recent work on the $\mathrm{V}(\mathrm{III})$ binding capabilities of some $[\mathrm{O}, \mathrm{O}]$ or $[\mathrm{N}, \mathrm{O}]$ donor biomolecules in solution using combined $\mathrm{pH}$-potentiometric and $\mathrm{UV}$-vis spectroscopic techniques.

\section{PREPARATION, STORAGE, AND USE OF V(III) STOCK SOLUTIONS}

Since commercially available sources of $\mathrm{V}(\mathrm{III})$ always contain some V(IV), a solution was obtained by dissolving $\mathrm{VCl}_{3}$ in deoxygenated $\sim 0.1 \mathrm{M} \mathrm{HCl}$ and $\mathrm{VO}^{2+}$ was removed by bubbling $\mathrm{H}_{2}$ in the presence of Pd sludge under argon atmosphere. The stock solution was filtered using Schlenk techniques and stored under an atmosphere of strictly deoxygenated argon. The V(III) stock solution was tested for its Pd content, and none was found by ICP-AES. The $\left[\mathrm{V}\left(\mathrm{H}_{2} \mathrm{O}\right)_{6}\right]^{3+}$ and $\mathrm{H}^{+}$concentration of the stock solution was determined by methods described elsewhere in detail [8]. The preparation of samples to be titrated, details of typical concentrations, ratios, experimental conditions, apparatuses, equipment, etc. were also described elsewhere in detail [8]. Concentration stability constants $\left(\beta_{\mathrm{pqr}}=\right.$ $\left.\left[\mathrm{M}_{\mathrm{p}} \mathrm{A}_{\mathrm{q}} \mathrm{H}_{\mathrm{r}}\right] /[\mathrm{M}]^{\mathrm{p}}[\mathrm{A}]^{\mathrm{q}}[\mathrm{H}]^{\mathrm{r}}\right)$ referring to the equilibrium $\mathrm{pM}+\mathrm{qA}+\mathrm{rH}=\mathrm{M}_{\mathrm{p}} \mathrm{A}_{\mathrm{q}} \mathrm{H}_{\mathrm{r}}\left(\mathrm{M}=\left[\mathrm{V}\left(\mathrm{H}_{2} \mathrm{O}\right)_{6}\right]^{3+}\right)$ were calculated with the aid of PSEQUAD computer program [9].

\section{HYDROLYSIS OF V(III)}

The hydrolysis of $\mathrm{V}(\mathrm{III})$ is extensive even below $\mathrm{pH}=2.0$ and was the subject of several previous studies [10-12]. Meier and coworkers [10] investigated the hydrolysis in detail at an ionic strength of $1.0 \mathrm{M}$ $(\mathrm{NaCl})$. However, as the speciation is sensitive to ionic strength, any studies under conditions different from those used previously requires reevaluation of the speciation of the hydrolysis parameters. We determined the stability constants of the soluble hydroxo complexes of $\mathrm{V}(\mathrm{III})$ in aqueous solution at $25.0^{\circ} \mathrm{C}$ and at an ionic strength of $0.2 \mathrm{M}(\mathrm{KCl})$ using combined $\mathrm{pH}$ potentiometry and UV-vis spectroscopy. The stability constants are given in Table 1, while the speciation is shown in Fig. 1. The dimeric species $\left[\mathrm{V}_{2}(\mathrm{OH})_{2}\right]^{4+}$ has an intensive absorption band at $430 \mathrm{~nm}[10,11]$, and its formation and decomposition is thus well defined in the $\mathrm{pH}$ range 1.5-4.5. These processes were monitored by UV-vis spectrophotometry at different $\mathrm{V}^{3+}$ concentrations in the $\mathrm{pH}$ range 1.8-4.2 and made the determination of the stability constant of the dimer possible. Combining these studies with the evaluation of the potentiometric results, the calculation of the full speciation was possible. Similarly to the results of Meier et al., the model presented here also contain $[\mathrm{V}(\mathrm{OH})]^{2+},\left[\mathrm{V}_{2}(\mathrm{OH})_{2}\right]^{4+},\left[\mathrm{V}(\mathrm{OH})_{2}\right]^{+}$, and $\left[\mathrm{V}_{3}(\mathrm{OH})_{8}\right]^{+}$ (Fig. 1). Despite several attempts, however, we did not find any indication of a significant formation of a tetrametric complex, $\left[\mathrm{V}_{4}(\mathrm{OH})_{12}\right]$, present in the previous model [10]. We attribute a narrow formation range of the tetramer, if it exists at all under our conditions of lower ionic strength, to explain why it was rejected during the evaluation of our experimental data. Taking into consideration the different ionic strengths, the values of the stability constants for the soluble hydroxo complexes of the V(III) system (Table 1) are in reasonably good agreement with those reported by Meier et al. [10]. 
Table 1 Stability constants of hydroxo complexes of V(III) $(\log \beta)$ at $25.0^{\circ} \mathrm{C}$ and at $I=0.20 \mathrm{M}(\mathrm{KCl})$ (standard deviations are in parentheses).

\begin{tabular}{lc}
\hline Complex & $\log \beta$ \\
\hline$[\mathrm{V}(\mathrm{OH})]^{2+}$ & $-2.17(2)$ \\
{$\left[\mathrm{V}_{2}(\mathrm{OH})_{2}\right]^{4+}$} & $-2.76(3)^{\mathrm{a}}$ \\
{$\left[\mathrm{V}(\mathrm{OH})_{2}\right]^{+}$} & $-6.27(3)$ \\
{$\left[\mathrm{V}_{3}(\mathrm{OH})_{8}\right]^{+}$} & $-21.96(4)$ \\
\hline
\end{tabular}

${ }^{a}$ Calculated from data obtained by UV-vis spectrophotometry.

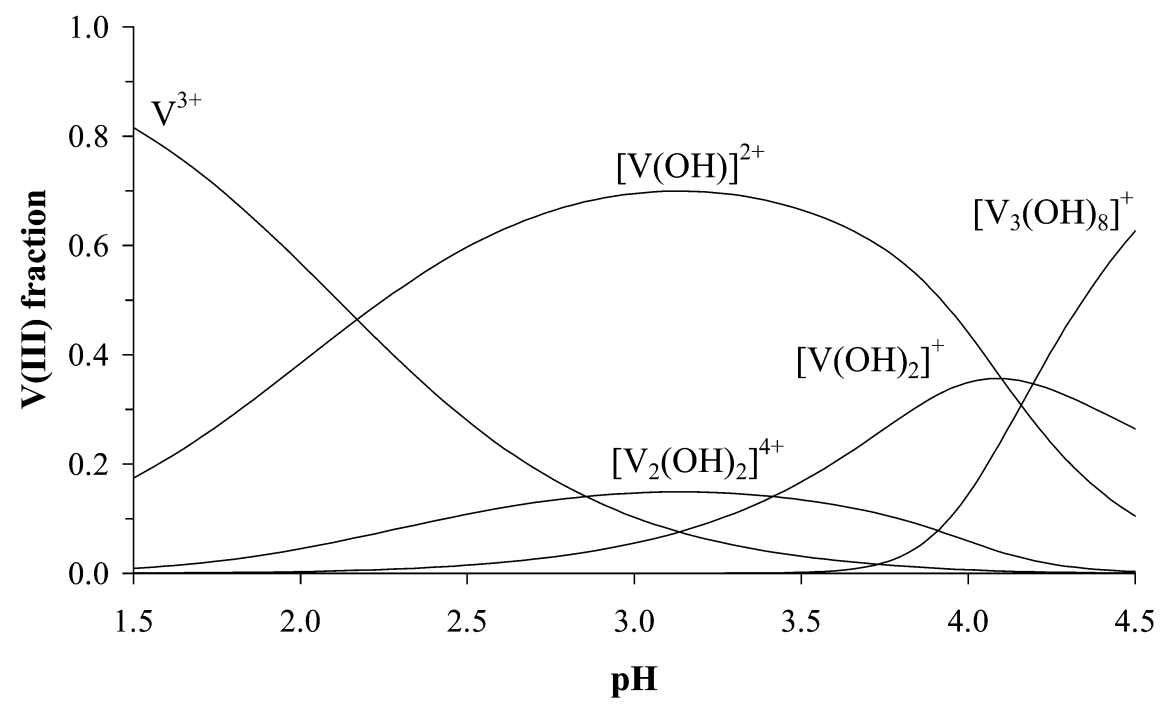

Fig. 1 Speciation curves of the hydroxo complexes of $\mathrm{V}(\mathrm{III}), c_{\mathrm{V}(\mathrm{III})}=4 \mathrm{mM}, I=0.2 \mathrm{M}(\mathrm{KCl}), T=25.0^{\circ} \mathrm{C}$.

\section{V(III) COMPLEXES OF WEAKLY COORDINATING LIGANDS}

The chemical formulae of the ligands studied are shown in Scheme 1. Beside the simplest amino acid, glycine (GLY), DL-aspartic acid (ASP), D-penicillamine (PEN), and DL-histidine (HIS) were also chosen in order to see whether the presence of any further donor atoms $\left(\mathrm{O}^{-}, \mathrm{S}^{-}\right.$, or $\mathrm{N}$, in order) influences the metal binding capability of a $\left[\mathrm{COO}^{-}, \mathrm{NH}_{2}\right]$ chelate. 
$\mathrm{H}_{2} \mathrm{~N}-\mathrm{CH}_{2}-\mathrm{COOH}$

GLY<smiles>NC(Cc1c[nH]cn1)C(=O)O</smiles><smiles>Cc1occc(=O)c1O</smiles>

MALT<smiles>CC(C)(S)C(N)C(=O)O</smiles>

PEN<smiles>O=C(O)c1ccccn1</smiles>

PIC<smiles>Cc1c(O)c(=O)ccn1C</smiles><smiles>NC(CC(=O)O)C(=O)O</smiles>

ASP<smiles>Cc1cccc(C(=O)O)n1</smiles>

MePIC<smiles>O=S(=O)([O-])c1cc(S(=O)(=O)O)cc(O)c1O</smiles>

TIR

\section{Scheme 1}

The results of the potentiometric titrations revealed that there is only weak interaction between the metal ion and these ligands. This is clearly reflected in the titration curves of the different systems, where the final $\mathrm{pH}$ values before observing precipitation of V(III) are always higher (GLY: 4.70, ASP: 5.50, PEN: 6.30, HIS: 8.90) at five-fold excess of ligand than for a sample of V(III) alone $(\mathrm{pH}=4.40)$ at $\mathrm{c}_{\mathrm{V}(\mathrm{III})}=4 \mathrm{mM}$. Despite numerous attempts, however, we could not obtain reliable models and stability constants with these ligands because of the very complicated equilibrium systems due to the parallel and extensive hydrolysis of the metal ion. The results also indicated, that beside the $\left[\mathrm{COO}^{-}, \mathrm{NH}_{2}\right]$ chelate with very weak V(III) binding capabilites, the presence of either carboxylate (ASP) or thiolate (PEN) is not sufficient enough to prevent the hydrolysis of $\mathrm{V}^{3+}$.

For HIS, treating the potentiometric data with various models that assumes simple 1:1 or 1:2 complexes always failed. This is in contrast with previous findings where mono and bis complexes with different protonation degree were detected [13]. Reasonable fit was achieved, however, assuming the formation of dinuclear complexes $\left(\mathrm{V}_{2} \mathrm{AH}_{-1}, \mathrm{~V}_{2} \mathrm{~A}_{2}, \mathrm{~V}_{2} \mathrm{~A}_{4} \mathrm{H}_{x}(x=2,0,-2,-3,-4)\right.$, where mostly either two or four ligands are coordinated to the metal centers. This preliminary model is also supported by a reported X-ray structure of a 2:4 complex that was isolated from aqueous solution at neutral $\mathrm{pH}$. The $\mathrm{V}-\mathrm{O}-\mathrm{V}$ core in this species is complexed with two tridentate and two bidentate ligands, and the overall stoichiometry is $\mathrm{V}_{2} \mathrm{~A}_{4} \mathrm{H}_{-2}$ (Scheme 2) [14,15]. Further proof is necessary, however, either to accept or to reject this tentative speciation. 
<smiles>NC(N)(NCCC(=O)[O-])OP1(N)(NCCC(=O)[O-])NCCN1</smiles>

$\left[\mathbf{V}_{2} \mathbf{A}_{\mathbf{4}} \mathbf{H}_{-2}\right]$

Scheme 2

\section{STRONG V(III) CHELATORS}

\section{Protonation processes of the ligands studied}

The stability constants calculated for the proton complexes of the ligands are summarized in Table 2 . The $\log K$ values are in good agreement with published data obtained at the same or similar experimental conditions [16-19]. The trends of the $\log K$ values were also discussed in previous studies and are in agreement with them [16-19].

Table 2 Stability constants of proton $(\log K)$ and V(III) $(\log \beta)$ complexes of the ligands at $25.0{ }^{\circ} \mathrm{C}$ and at $I=0.20 \mathrm{M}(\mathrm{KCl})$ (standard deviations are in parentheses).

\begin{tabular}{lccccc}
\hline Complex & PIC & MePIC & MALT & DHP & TIR \\
\hline $\log K(\mathrm{HA})$ & $5.16(1)$ & $5.79(1)$ & $8.46(1)$ & $9.75(1)$ & $12.3(1)$ \\
$\log K\left(\mathrm{H}_{2} \mathrm{~A}\right)$ & $\sim 1$ & $\sim 1$ & - & $3.67(1)$ & $7.47(3)$ \\
{$[\mathrm{VA}]$} & $6.28(6)$ & $5.98(5)$ & $10.38(4)$ & $13.36(3)$ & $18.65(2)$ \\
{$\left[\mathrm{VAH}_{-1}\right]$} & $3.87(3)$ & $2.67(3)$ & $6.39(9)$ & $9.10(6)$ & $13.69(9)$ \\
{$\left[\mathrm{VA}_{2}\right]$} & $12.16(4)$ & - & $18.97(2)$ & $24.45(4)$ & $32.53(2)$ \\
{$\left[\mathrm{VA}_{2} \mathrm{H}_{-1}\right]$} & $9.06(4)$ & $6.90(4)$ & $13.1(1)$ & $18.39(6)$ & $24.80(9)$ \\
{$\left[\mathrm{VA}_{2} \mathrm{H}_{-2}\right]$} & $1.1(2)$ & - & - & - & - \\
{$\left[\mathrm{VA}_{3}\right]$} & $16.63(9)$ & - & $26.01(3)$ & $33.39(5)$ & $43.10(3)$ \\
Fitting & 0.00505 & 0.00511 & 0.00674 & 0.00649 & 0.00899 \\
No. of points & 214 & 220 & 145 & 105 & 184
\end{tabular}

aThe average difference between the calculated and experimental titration curves expressed in $\mathrm{cm}^{3}$ of the titrant.

\section{V(III) complexes of picolinic (PIC) and 6-methylpicolinic acid (MePIC)}

Both ligands can form stable [N,O] chelate(s) with $\mathrm{V}(\mathrm{III})$ and suppress its hydrolysis strongly in the acidic $\mathrm{pH}$ range. The stability constants $(\log \beta)$ of the complexes formed can be seen in Table 2 , the speciation curves are shown in Figs. 2 and 3. The data in Table 2 and the speciation curves in Figs. 2 and 3 indicate a complexation scheme involving the formation of mono and bis complexes with different protonation degree. In the PIC system, the complexation starts with the parallel formation of [VA $]^{2+}$ and $\left[\mathrm{VA}_{2}\right]^{+}$at $\mathrm{pH}<2$. In these species, the ligands coordinate via the carboxylate and pyridine $\mathrm{N}$ and form five-membered chelate(s). On increasing $\mathrm{pH}$, mixed hydroxo species $\left[\mathrm{VAH}_{-1}\right]^{+}$and $\left[\mathrm{VA}_{2} \mathrm{H}_{-1}\right]$ are formed with the deprotonation of one of the water molecules in the coordination sphere of the metal ion. Beside $\left[\mathrm{VA}_{2} \mathrm{H}_{-1}\right]$, which predominates over the $\mathrm{pH}$ range 3.0-7.0, considering a tris complex, $\left[\mathrm{VA}_{3}\right]$, improved the fit significantly during the calculations. In this species, the three ligands occupy the positions around $\mathrm{V}(\mathrm{III})$ forming $[\mathrm{N}, \mathrm{O}]$ chelates in an octahedral arrangement. It is well documented 


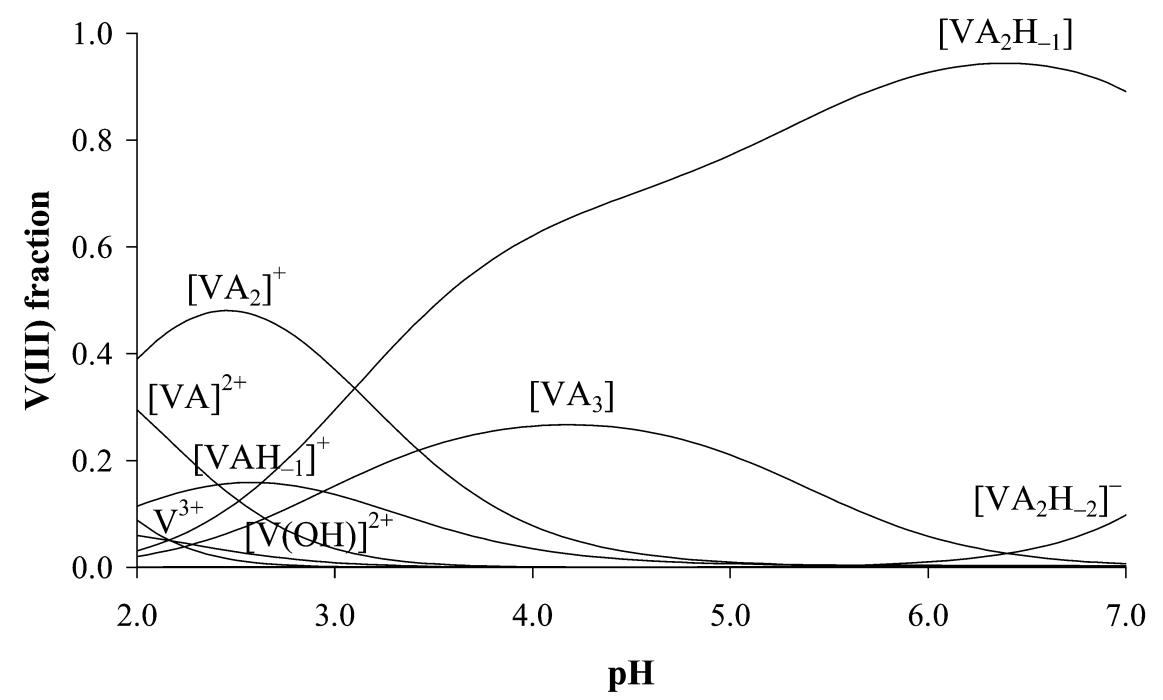

Fig. 2 Speciation curves of the complexes formed in the V(III)-PIC system at a 1:4 ratio, $c_{\mathrm{PIC}}=4 \mathrm{mM}, I=0.2 \mathrm{M}$ $(\mathrm{KCl}), T=25.0^{\circ} \mathrm{C}$.

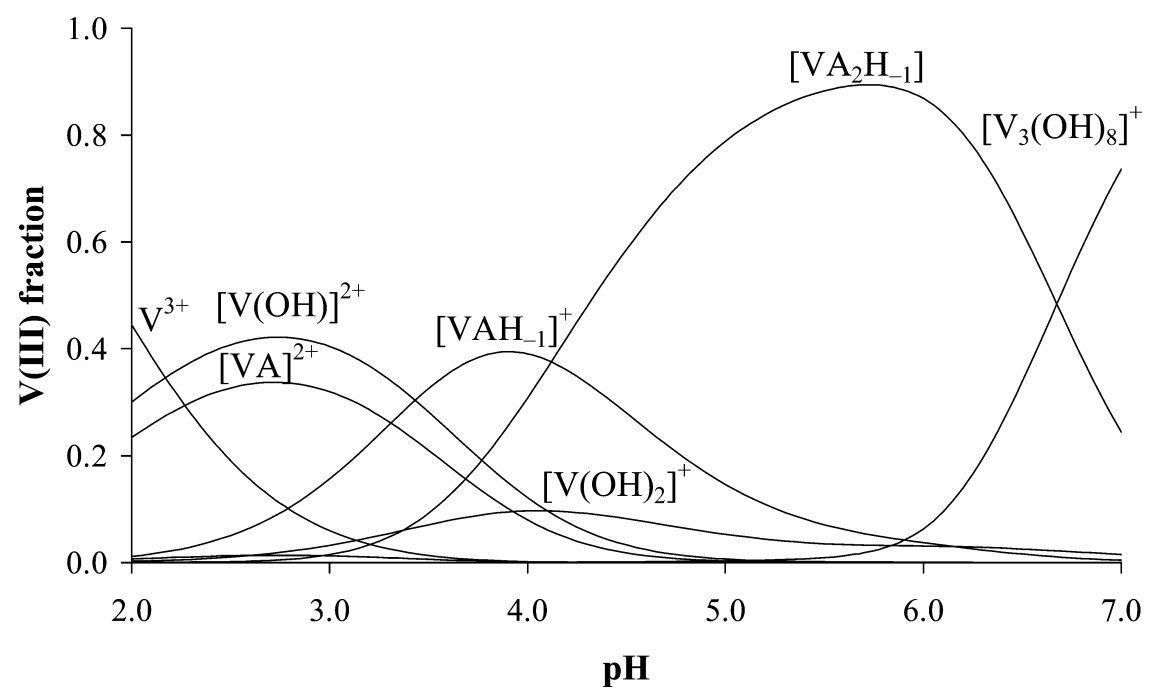

Fig. 3 Speciation curves of the complexes formed in the V(III)-MePIC system at a 1:4 ratio, $c_{\mathrm{MePIC}}=2 \mathrm{mM}, I=$ $0.2 \mathrm{M}(\mathrm{KCl}), T=25.0^{\circ} \mathrm{C}$.

that $\left[\mathrm{VA}_{3}\right]$ can precipitate from more concentrated aqueous solutions after treating V(III) with PIC [20]. This fact, however, does not contradict the speciation model presented in Fig. 2 because our model calculations demonstrated that at $c_{\mathrm{V} \text { (III) }}=100 \mathrm{mM}$ and at $1: 4$ metal-to-ligand ratio actually [ $\mathrm{VA}_{3}$ ] becomes the predominant species in the range $\mathrm{pH} 2.5-6.5$.

The complex formation was also monitored by UV-vis spectrophotometry. Typical spectra recorded at different $\mathrm{pH}$ values are depicted in Fig. 4. The intensity of the bands first increases on increasing $\mathrm{pH}$, then decreases above $\mathrm{pH} \sim 6.5$ (for clarity, these latter curves are not shown in Fig. 4). The spectra exhibit three bands at 375,515 , and $628 \mathrm{~nm}(\mathrm{pH}=5.07)$, which are characteristic of V(III) in an octahedral environment [20]. The stability constants of complexes having the largest contribution to the spectrum could also be determined by keeping the $\log \beta$ value of $[\mathrm{VA}]^{2+}$ obtained from $\mathrm{pH}$ poten- 


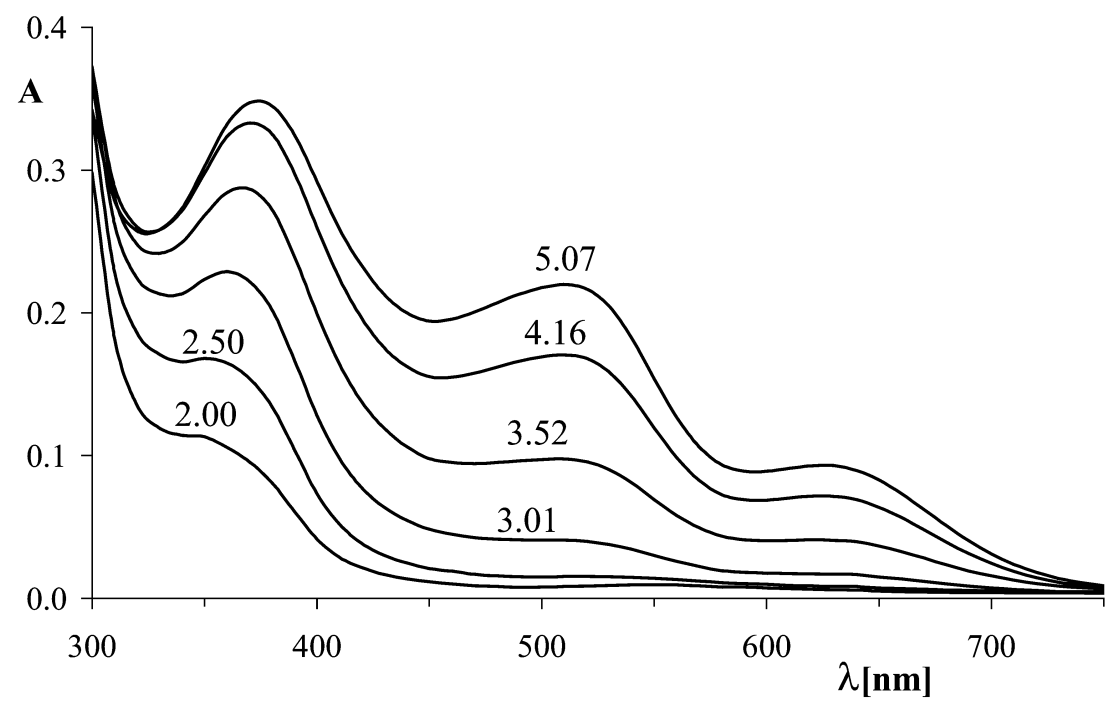

Fig. 4 UV-vis absorption spectra recorded in the V(III)-PIC system at a 1:4 ratio, $c_{\text {PIC }}=4 \mathrm{mM}, I=0.2 \mathrm{M}(\mathrm{KCl})$, $T=25.0{ }^{\circ} \mathrm{C}, \mathrm{pH}$ values are indicated by numbers.

tiometry constant during the calculation. The stability constants $(\log \beta)$ obtained in this way for $\left[\mathrm{VAH}_{-1}\right.$ ] [4.0(1)]; $\left[\mathrm{VA}_{2}\right][12.4(1)]$, and $\left[\mathrm{VA}_{2} \mathrm{H}_{-1}\right][9.2(1)]$ are in good agreement with the corresponding values in Table 1 and therefore confirm the model relying on potentiometric titrations.

With MePIC, the complex formation starts at higher $\mathrm{pH}$ compared to PIC. At $c_{\text {MePIC }}=4 \mathrm{mM}$ concentration, red microcrystalline precipitate was observed. The titrations therefore were carried out in the concentration range of $c_{\text {MePIC }}=1-2 \mathrm{mM}$ until precipitation occurred. Two models could be used for the evaluation of the potentiometric data with an equally good fit. The difference between these two models is that $\left[\mathrm{VA}_{2} \mathrm{H}_{-1}\right]$ is present in the first, whereas it is replaced by $\left[\mathrm{VA}_{3}\right]$ in the second. Although the strong analogy to the PIC system would suggest that the precipitate the tris complex again, electrospray ionization/mass spectroscopy (ESI/MS) measurements carried out on the solid samples clearly demonstrated that stoichiometry of the precipitate is in fact $\left[\mathrm{VA}_{2} \mathrm{H}_{-1}\right]$ (Fig. 5). The speciation curves of this system are depicted in Fig. 3, and the stability constants of the complexes are summmarized in Table 1.

Comparison of the stability constants for the complexes of the two ligands indicates that PIC forms more stable [N,O] chelate with $\mathrm{V}(\mathrm{III})$ than MePIC. This is clearly seen in the equilibrium constants of the proton displacement reactions $\left(\mathrm{V}^{3+}+\mathrm{HA}=\mathrm{VA}^{2+}+\mathrm{H}^{+}\right)$, which take the different basicities of the ligands into consideration. Using the data in Table 2, the calculated equilibrium constants (PIC: $\log K=1.12$; MePIC: $\log K=0.19$ ) reveal that PIC forms more stable chelate than MePIC does. A similar trend can be seen when the preference of the coordination of the second ligand to the metal ion is compared. Since $\left[\mathrm{VA}_{2}\right]^{+}$is not formed with MePIC, only the constants referring to the following equilibrium can be used: $\mathrm{VAH}_{-1}{ }^{+}+\mathrm{HA}=\mathrm{VA}_{2} \mathrm{H}_{-1}+\mathrm{H}^{+}$. The derived equilibrium constants (PIC: $\log$ $K=0.03$; MePIC: $\log K=-1.56$ ) clearly demonstrate the more favored coordination of the second PIC ligand over MePIC to the metal ion. The difference between the ligands in binding V(III) can be explained with higher steric hindrance and the solvation decreasing effect of the methyl group of the MePIC ligand [16].

Comparison of Figs. 2 and 3 also indicates that, unlike with PIC, hydrolysis of some free V(III) takes place with MePIC due to the weaker metal binding strength of the latter ligand. The higher basicity of MePIC, on the other hand, is reflected in the differences of the $\mathrm{p} K_{\mathrm{VA}}$ values (PIC: 2.41 ; MePIC: 3.31 ) indicating the slightly stronger ability of MePIC to prevent [VA $]^{2+}$ from hydrolyzing. 


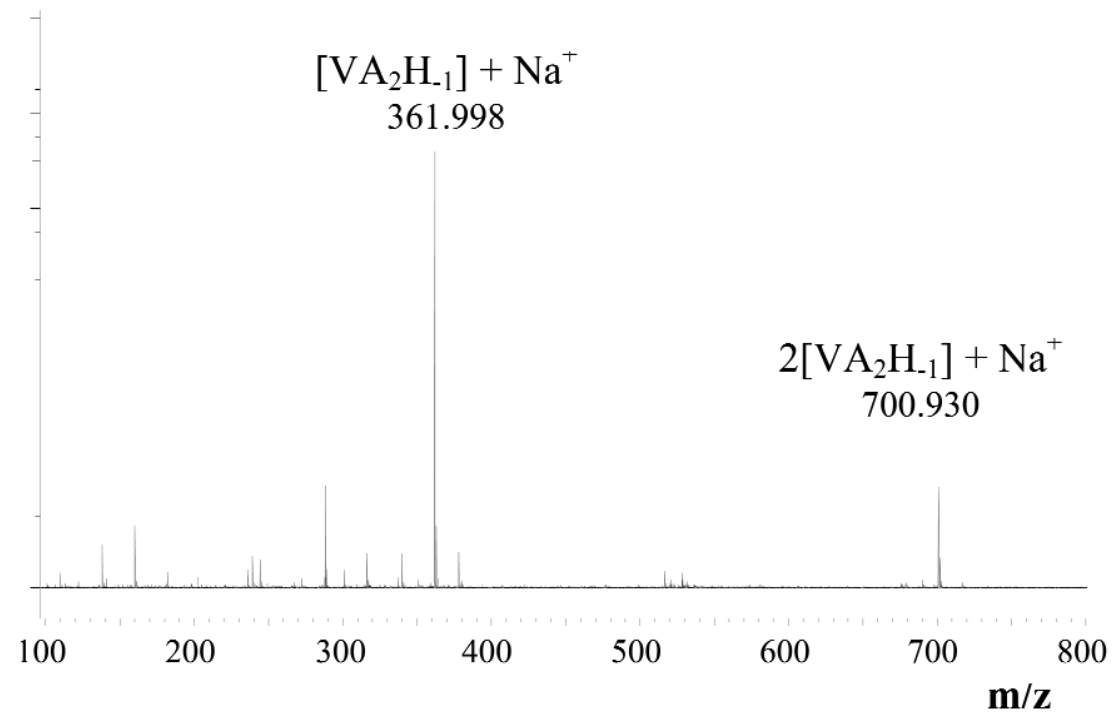

Fig. 5 ESI/MS spectrum of the complex isolated from the V(III)-MePIC system at $\mathrm{pH}=5.5$.

\section{V(III) complexes of maltol (MALT), 1,2-dimethyl-3-hydroxy-4-(1H)-pyridinone (DHP), or tiron (TIR)}

In previous studies, preparation and characterization of air-stable (MALT, DHP) or air-sensitive (catechol) complexes with $\mathrm{VL}_{3}$ stoichiometry were carried out $[6,21]$. These ligands were found to form stable complexes with V(III) also in aqueous solution, similarly to the observations with VO(IV) [15-17]. Although precipitation was observed with MALT at $\mathrm{pH}=8.4$ at $1: 1$ ratio, the other two ligands were found to be able to prevent the hydrolysis of V(III) even better as the potentiometric titrations could be performed until $\mathrm{pH} 11.0$ in equimolar solutions. In all cases, models involving 1:1, 1:2, and 1:3 complexes could be used to fit the titration curves best; assuming the formation of mixed hydroxo species improved the fit significantly. The stability constants of the species formed are summarized in Table 2, a representative speciation diagram for the TIR system is shown in Fig. 6. 


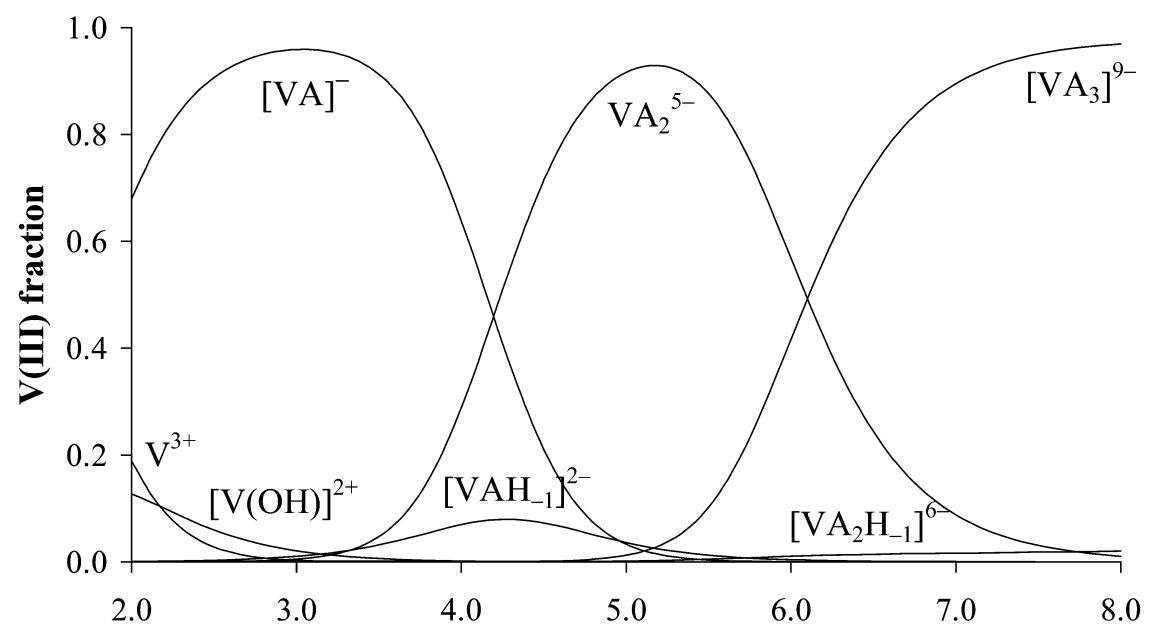

Fig. 6 Speciation curves of the complexes formed in the V(III)-TIR system at 1:3 ratio, $c_{\mathrm{TIR}}=3 \mathrm{mM}, I=0.2 \mathrm{M}$ $(\mathrm{KCl}), T=25.0^{\circ} \mathrm{C}$.

With all of these ligands, the interaction starts with the formation of 1:1 complexes having [O,O] chelates. With the coordination of a second or third ligand, the appropriate bis or tris complexes are formed as major species on increasing $\mathrm{pH}$. Since the basicities of the donor groups of the ligands are rather different and the chelates being formed have different chemical nature, a theoretical distribution of V(III) among these three chelators was calculated using the data in Table 2 instead of the direct comparison of the stability constants of the three models. This speciation in Fig. 7 reveals that MALT with the smallest basicity of the donor group binds V(III) relatively strongly only in the pH range 2.0-3.0. DHP is more potent as it is able to coordinate to the metal ion in a wide $\mathrm{pH}$ range of 3.0-7.0 in the form of 1:2 or 1:3 complexes. The phenolate-type O-donors of TIR having the largest basicity among these ligands are very effective in binding of $\mathrm{V}$ (III), but above $\mathrm{pH}=7.0$ only; under acidic conditions, the proton competition yields small apparent stability constants for the V(III)-TIR complexes. In the DHP system at 1:1 ratio, the complex formation was also monitored by UV-vis spectrophotometry in the $\mathrm{pH}$ range $0.8-2.0$, and a stability constant of 13.4(1) could be calculated for the [VA] ${ }^{2+}$ species in excellent agreement with that obtained from $\mathrm{pH}$ potentiometry. Similarly, the successive coordination of the ligands was accompanied by intensive change in the absorption spectra for TIR. Analysis of the spectrophotometric data yielded stability constant values of 18.7(1), 32.1(1), and 42.3(1), for the major 1:1, 1:2, and 1:3 parent complexes. These are in good agreement with those obtained from potentiometry again and confirm the data listed in Table 2. Comparison of the $\log \left(K_{1} / K_{2}\right)$ values (MALT: 1.79; DHP: 2.27; TIR: 4.77) obtained from the data in Table 2 shows that the preference for the formation of the bis complex decreases in the order MALT $>$ DHP $>>$ TIR. For TIR, beside steric hindrance, electronic reasons may also play important role. Unlike with MALT or DHP, where charge compensation takes place when $\mathrm{VA}_{2}$ is formed $\left(\mathrm{VA}^{2+}+\mathrm{A}^{-}=\mathrm{VA}_{2}^{+}\right)$, with TIR the negative charge of $\mathrm{VA}^{-}$increases during this reaction $\left(\mathrm{VA}^{-}+\mathrm{A}^{4-}=\mathrm{VA}_{2}{ }^{5-}\right)$.

Beside the parent species, mixed hydroxo complexes with the stoichiometry of $\mathrm{VAH}_{-1}$ or $_{\mathrm{VA}_{2} \mathrm{H}_{-1}}$ can also be detected as minor species in all three systems. Comparison of the $\mathrm{p} K_{\mathrm{VA}}(3.99,4.26$, and 4.96) or $\mathrm{p} K_{\mathrm{VA}_{2}}(5.86,6.06$, and 7.73) values (calculated using the data in Table 2) indicates that in the order MALT, DHP, TIR the metal complexes show increased resistance against hydrolysis, which follows the trend of increasing basicities of the ligands. 


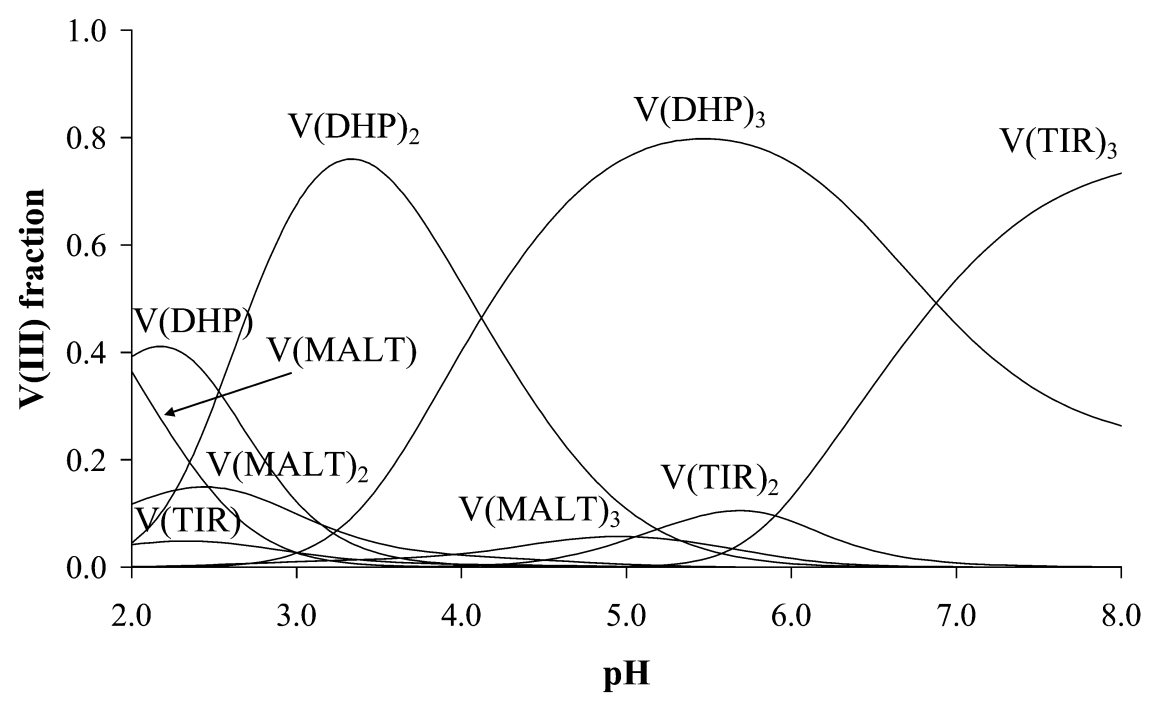

Fig. 7 Calculated species distribution for V(III)-MALT-DHP-TIR system, $c_{\mathrm{V}(\mathrm{III})}=1 \mathrm{mM}, c_{\mathrm{MALT}}=c_{\mathrm{DHP}}=c_{\mathrm{TIR}}=$ $3 \mathrm{mM}, I=0.2 \mathrm{M}(\mathrm{KCl}), T=25.0^{\circ} \mathrm{C}$.

\section{CONCLUSIONS}

The results of this work demonstrate that simple amino acids are weak V(III) binders. The presence of the common coordinating side chains (e.g., imidazole $\mathrm{N}$ of HIS) may improve the coordination capability of the ligand, but the simultaneous hydrolytic processes of V(III) make the evaluation of the pH-potentiometric data difficult. Tentative measurements in the V(III)-DHP-amino acid ternary systems revealed that occupying two sites in the coordination sphere of the metal ion by strongly coordinating ligand suppresses the hydrolysis of V(III) significantly, but the formation of mixed ligand complexes is still hindered.

Replacement of the amino group by aromatic $\mathrm{N}$ resulted in significant improvement of the metal binding strength of the $\left[\mathrm{N}_{\mathrm{Ar}}, \mathrm{O}\right]$ chelate as it was found with PIC or MePIC. Very strong metal ion-ligand interaction was also found with dipicolinic or 4-OH-dipicolinic acid capable of tridentate $\left[\mathrm{O}, \mathrm{N}_{\mathrm{Ar}}, \mathrm{O}\right]$ coordination [8].

MALT, DHP, or TIR, which all have $[\mathrm{O}, \mathrm{O}]$ donor sets, were also found to form stable complexes with $\mathrm{V}$ (III) and able to prevent its hydrolysis even at physiological $\mathrm{pH}$. Comparison of the metal binding properties of these ligands with different basicities indicated that the complex formation shifts below $\mathrm{pH} \sim 2$ with ligands having donor groups of low basicity, while those with high basicity can bind the metal ion under basic conditions too.

In order to compare the $\mathrm{V}(\mathrm{III})$ binding strengths of the ligands under investigation at $\mathrm{pH}=7.0$, the amount of the complexed metal ion is calculated in each system. This is shown as whole bars in Fig. 8. It may be more informative, however, to consider the amount of the neutral complexes, which may cross membranes easier with passive transport than charged ones. This is also depicted in the form of dark parts on the bars in Fig. 8, and indicates that PIC, MALT, and DHP are the best candidates as carrier molecules in this simple model. 


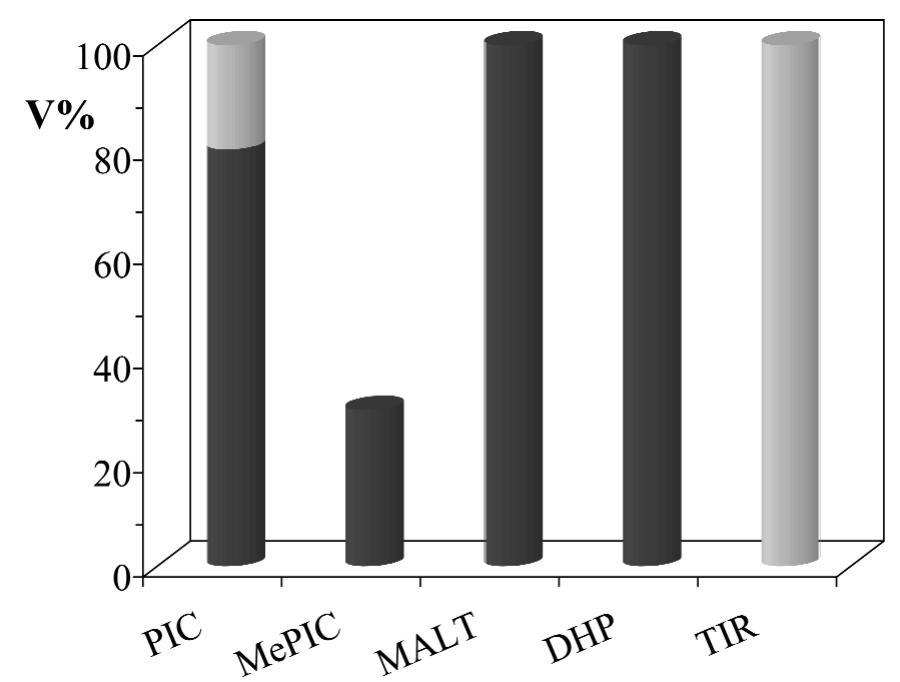

Fig. 8 Fraction of complexed V(III) (whole bars) or fraction of the neutral V(III) complexes (dark parts of the bars) in various strong $\mathrm{V}(\mathrm{III})$ chelator systems at $\mathrm{pH}=7.0$.

\section{ACKNOWLEDGMENTS}

This work was supported by the Hungarian Science Research Fund (OTKA F32235, TS 040685). PB gratefully acknowledges the Hungarian Academy of Sciences for a János Bolyai Research Fellowship.

\section{REFERENCES}

1. C. Orvig, K. H. Thompson, M. Battel, J. H. McNeill. In Metal Ions in Biological Systems, Vol. 31, A. Sigel and H. Sigel (Eds.), pp. 575-594, John Wiley, New York (1995).

2. D. Rehder. Coord. Chem. Rev. 297-322 (1999).

3. K. H. Thompson and C. Orvig. J. Chem. Soc., Dalton Trans. 2885-2892 (2000).

4. M. Rangel, A. Tamura, C. Fukushima, H. Sakurai. J. Biol. Inorg. Chem. 6, 128 (2001).

5. D. Rehder, J. Costa Pessoa, C. F. G. C. Geraldes, M. M. C. A. Castro, T. A. Kabanos, T. Kiss, B. Meier, G. Micera, L. Pettersson, M. Rangel, A. Salifoglou, I. Turel, D. Wang. J. Biol. Inorg. Chem. 7, 384-396 (2002).

6. M. Melchior, S. J. Rettig, B. D. Liboiron, K. H. Thompson, V. G. Yuen, J. H. McNeill, C. Orvig. Inorg. Chem. 40, 4686 (2001).

7. A. Papaioannou, M. Manos, S. Karkabounas, R. Liasko, A. M. Evangelou, I. Correia, V. Kalfakakou, J. Costa Pessoa, T. Kabanos. J. Inorg. Biochem. 98, 959-968 (2004).

8. P. Buglyó, D. C. Crans, E. M. Nagy, R. L. Lindo, L. Yang, J. J. Smee, L.-H. Chi, M. E. Godzala III, G. R. Willsky. Inorg. Chem. 44, 5416-5427 (2005).

9. L. Zékány and I. Nagypál. In Computational Methods for the Determination of Stability Constants, D. Leggett (Ed.), Plenum, New York (1985).

10. R. Meier, M. Boddin, S. Mitzenheim, K. Kanamori. In Metal Ions in Biological Systems, Vol. 31, A. Sigel and H. Sigel (Eds.), pp. 45-88, John Wiley, New York (1995).

11. L. Pajdowski. Roczniki Chemii. 37, 1351-1361 (1963).

12. L. Pajdowski and B. Jezowska-Trzebiatowska. J. Nucl. Inorg. Chem. 28, 433-442 (1966).

13. K. Bukietynska, Z. Karwecka, H. Podsiadly. Polyhedron. 16, 2613-2620 (1997).

14. K. Kanamori, M. Teraoka, H. Maeda, K. Okamoto. Chem. Lett. 1731-1734 (1993).

15. R. S. Czernuszewicz, Q. Yan, M. R. Bond, C. J. Carrano. Inorg. Chem. 33, 6116-6119 (1994). 
16. E. Kiss, E. Garribba, G. Micera, T. Kiss. J. Inorg. Biochem. 78, 97-108 (2000).

17. P. Buglyó, E. Kiss, I. Fábián, T. Kiss, D. Sanna, E. Garribba, G. Micera. Inorg. Chim. Acta. 306, 174 (2000).

18. P. Buglyó, T. Kiss, E. Kiss, D. Sanna, E. Garribba, G. Micera. J. Chem. Soc., Dalton Trans. 2275-2282 (2002).

19. P. Buglyó and T. Kiss. J. Coord. Chem. 22, 259-268 (1991).

20. M. Chatterjee, S. Ghosh, A. K. Nandi. Polyhedron. 16, 2917-2923 (1997).

21. S. R. Cooper, Y. B. Koh, K. N. Raymond. J. Am. Chem. Soc. 104, 5092-5102 (1982). 